\title{
Evaluation of the appropriate predictive contributor and diagnostic threshold for the cardio-metabolic syndrome in Chinese Uyghur adults
}

Zhoubin Zhang ${ }^{1 \dagger}$, Shujun Fan ${ }^{1 \dagger}$, Zhenxiang Xue ${ }^{2}$, Jun Yuan ${ }^{1}$, Ziyan Zhou', Tongmin Wang ${ }^{3}$, Junling Liu ${ }^{3}$, Ayxamgul Bawudun'², Nazibam Nurmamat ${ }^{2}$, Yuzhong Wang ${ }^{2}$ and Zhicong Yang ${ }^{1 *}$

\begin{abstract}
Background: Several epidemiological studies have suggested that optimal obesity and visceral adiposity indicators and their cut-off values to predict cardio-metabolic risks varied among different ethnic groups. However, few studies have investigated the associations of anthropometric indices with cardio-metabolic risks in Chinese Uyghur adults, and the results were inconsistent.

Methods: Between May and September 2016, a total of 4664 subjects aged $\geq 18$ years old were recruited from Northwest China. Anthropometric indices and cardio-metabolic risk factors were measured by trained personnel. Partial correlation analyses and logistic regression analyses were used to evaluate the associations of anthropometric indices with cardio-metabolic risk factors. Receiver operating characteristic analysis was used to compare the abilities of different anthropometric indices to predict cardio-metabolic risk factors, and to determine the optimal cut-off values.

Results: The prevalence of metabolic syndrome was $39.41 \%$ in Uyghur adults from Xinjiang Uyghur Autonomous Region. Waist circumference (WC) performed better than other obesity indices in predicting the cardio-metabolic risk factors, and the optimal cut-off value of WC to diagnose metabolic syndrome risk factors was $86.50 \mathrm{~cm}$ for women and $90.50 \mathrm{~cm}$ for men.
\end{abstract}

Conclusions: Our study suggests that WC had the strongest predictive power for identifying cardio-metabolic risks in Xinjiang Uyghur adults. Further well-designed longitudinal studies are needed to confirm our findings.

Keywords: Anthropometric indices, Cardio-metabolic syndrome, Cut-off points, Uyghur

\section{Background}

Cardio-metabolic syndrome, characterized by a cluster of metabolic abnormalities including obesity, elevated blood pressure, glucolipid metabolism disorders, and insulin resistance, can increase the risk of type 2 diabetes mellitus, cardiovascular disease (CVD), and all-cause mortality [1]. The syndrome has become a major public health problem in China, partially due to the changing

\footnotetext{
* Correspondence: yangzc@gzcdc.org.cn

${ }^{\dagger}$ Zhoubin Zhang and Shujun Fan contributed equally to this work.

${ }^{1}$ Guangzhou Center for Disease Control and Prevention, No. 1 Qide Road,

Guangzhou, Baiyun Area, Guangzhou 510440, China

Full list of author information is available at the end of the article
}

life styles and westernized dietary habits. As shown in several national representative surveys, the overall prevalence of metabolic syndrome (MetS) in Chinese adults has increased from $13.7 \%$ in 2001 [2] to $24.2 \%$ in 2014 [3], and shows gender, ethnic and geographical variations $[4,5]$.

The causes of cardio-metabolic syndrome are complex and are related to numerous environmental and genetic factors. For example, older age, tobacco or alcohol use, physical inactivity, unhealthy dietary habits, and air pollution exposure have been reported to be correlated with increased risk of MetS and other CVD [6, 7]. In addition, several studies have also reported that

(c) The Author(s). 2019 Open Access This article is distributed under the terms of the Creative Commons Attribution 4.0 International License (http://creativecommons.org/licenses/by/4.0/), which permits unrestricted use, distribution, and reproduction in any medium, provided you give appropriate credit to the original author(s) and the source, provide a link to the Creative Commons license, and indicate if changes were made. The Creative Commons Public Domain Dedication waiver (http://creativecommons.org/publicdomain/zero/1.0/) applies to the data made available in this article, unless otherwise stated. 
participant with genetic mutations, such as lipoprotein lipase (LPL) rs295C allele, apolipoprotein A-V (APOA5) rs2266788C allele, and cholesteryl ester transfer protein (CETP) rs173539T allele, might have a higher odd of MetS [8]. Among them, obesity, especially visceral adiposity is considered to be the predominant determinant of cardio-metabolic risks [1]. Body mass index (BMI), waist circumference (WC), hip circumference $(\mathrm{HC})$, and waist-to-hip ratio (WHR) are the most used anthropometric indices to reflect obesity or visceral adiposity, and to predict cardio-metabolic risks [9-11]. Although WC is the most commonly accepted anthropometric index to predict cardio-metabolic risks, several epidemiologic studies have suggested that optimal obesity and visceral adiposity indicators and their cut-off values varied among different ethnic groups [12, 13]. Xinjiang Uyghur Autonomous Region is located in the northwest frontier area of China, where Uyghur population is the major inhabitant minority group. Prevalence rates of CVD and MetS were often reported to be high among the Uyghur population due to their specific lifestyles, environmental exposure, and genetic background [14-16]. Previous surveys have revealed that due to the cold weather and heavy labor, Xinjiang residents consume less vegetable, but greater amounts of red meat (beef and mutton), dairy foods (cheese and milk tea) and pasta, which were associated with higher risks of CVD and MetS [14]. Additionally, many genetic polymorphisms have also been linked to MetS among Uyghur population $[15,16]$. For example, Zohra et al. found that the peroxisome proliferative active receptor gamma gene polymorphism was associated with a higher odd of MetS among Uyghur adults [15]. And Pan et al. observed that angiotensin converting enzyme 2 polymorphisms were associated with MetS individual components (e.g., hypertension and dyslipidemia) in people living in Xinjiang province [16]. However, awareness, treatment, and control of these disorders were lower because of undeveloped economics, less access to health care, and ineffective prevention strategies.

Evidence concerning which anthropometric index is an effective indicator for predicting cardio-metabolic risks in Uyghur population is very limited. To the best of our knowledge, only three studies investigated the association of anthropometric indices with MetS in Chinese Uyghur adults and reported inconsistent results [13, 17, 18]. Specifically, a cross-sectional study of 4767 Uyghur adults reported that waist-to-height ratio (WHtR) was the best predictor of MetS, when compared with WHR, BMI and body adiposity index [13]. However, the other two studies showed that WC was the optimal anthropometric index for Uyghur adult residents $[17,18]$. This indicates that more studies remain needed. Therefore, in this study we sought to compare the relationship of four different anthropometric indices (WC, HC, BMI, WHR) with cardio-metabolic risks and its individual components, and to identify the appropriate cut-off points of these indices for screening cardio-metabolic risks and its individual components. We selected Kashgar region as the study site, in which 98\% of the population are Uyghurs, thus providing a ubiquitous opportunity to fulfill our study aims.

\section{Methods \\ Study participants and inclusion criteria}

Between May and September 2016, a total of 4772 individuals aged 18 years or older were recruited from Shufu county. The county consists of 10 towns with 123 villages and is located in Kashgar city of Xinjiang Uyghur Autonomous Region, which is an important political, economic, and cultural center in northwestern China. Over 290,000 registered residents are living in Shufu county, of whom $98 \%$ are Uyghurs. A stratified cluster sampling method was applied to recruit study participants. First, we randomly selected one village from each of the 10 towns of the county using the random number method. Then, residents who aged $\geq 18$ years old and lived in the county for at least two years were selected from each of the selected villages. The sampling frame resulted in the selection of 5087 individuals, of whom 4772 finished the questionnaire survey, yielding a response rate of $93.81 \%$. We excluded participants who were not Uyghur nationality, had a history of myocardial infarction, renal failure, chronic liver disease, or other malignant diseases, and those who were in pregnancy, lactation, and weight control women. Finally, a total of 4664 participants were included in the present analysis. The study was in accordance with the principles stipulated by the Declaration of Helsinki, and was approved by the Ethics Committee of Guangzhou Center for Disease Control and Prevention prior to the present study (Identification code: GZCDC-ER[A]2016007). A written informed consent was obtained from all participants before all specimens and survey data were collected.

\section{Anthropometric measures}

The anthropometric indices were examined with the participants in light clothing after an overnight fast using standard techniques and equipments by well-trained observers. Weight and height were measured using an electronic scale (Seca Limited) and a stadiometer (Seca Limited) in bare feet to the nearest $0.1 \mathrm{~kg}$ and $0.1 \mathrm{~cm}$, respectively. BMI was calculated as weight divided by the square of height, in kilograms per square meters $\left(\mathrm{kg} / \mathrm{m}^{2}\right)$. WC was measured at the midpoint between the lower costal margin and the superior margin of the iliac crest [19]. HC was measured at the level of largest 
posterior extension of the gluteal muscles [20]. WHR was calculated as WC $(\mathrm{cm})$ divided by $\mathrm{HC}(\mathrm{cm})$.

\section{Cardio-metabolic risk factors and their definitions}

Systolic blood pressure (SBP) and diastolic blood pressure (DBP) were measured based on the standardized procedural guidelines after $15 \mathrm{~min}$ of rest in the sitting position, using a mercury-column sphygmomanometer [21, 22]. The average of 3 consecutive measurements in one selected arm to the nearest $2 \mathrm{mmHg}$ was recorded. All participants were advised not to drink tea, coffee, alcohol, or to consume tobacco, and to exercise for at least $30 \mathrm{~min}$ before blood pressure (BP) measurement. At the same time, all participants were asked for permission to collect blood samples for biochemical analysis after an overnight fast of $>8 \mathrm{~h}$. The concentrations of fasting blood glucose (FBG), total cholesterol (TC), triglycerides (TG), high-density lipoprotein (HDL-C) and low-density lipoprotein (LDL-C) were determined using a Roche Autoanalyzer (Cobas c702 type; Roche Ltd.; Germany) in local community health service centers as well as Guangzhou Center for Disease Control and Prevention.

Cardio-metabolic risk factors included: (1) high BP (SBP $\geq 130 \mathrm{mmHg}$ and/or $\mathrm{DBP} \geq 85 \mathrm{mmHg}$, and/or on antihypertensive medications); (2) high TG (TG $\geq 1.7$ $\mathrm{mmol} / \mathrm{L}$ ); (3) high $\mathrm{FBG}$ ( $\mathrm{FBG} \geq 5.6 \mathrm{mmol} / \mathrm{L}$ or taking medication for diabetes mellitus); (4) low HDL-C (HDL-C $<1.03 \mathrm{mmol} / \mathrm{L}$ for men, and $<1.30 \mathrm{mmol} / \mathrm{L}$ for women) [23]; (5) high TC (TC $\geq 5.18 \mathrm{mmol} / \mathrm{L})$; and (6) high LDL-C (LDL-C $\geq 3.37 \mathrm{mmol} / \mathrm{L})$ [24].

In main analysis, we defined MetS according to the International Diabetes Federation (IDF) criterion [23], that is, central obesity (WC $\geq 90 \mathrm{~cm}$ for men and $\mathrm{WC} \geq 80 \mathrm{~cm}$ for women) plus any two or more of the following components: high BP, high TG, high FBG, and low HDL-C. We also performed sensitivity analysis by defining MetS according to the updated National Cholesterol Education Program/Adult Treatment Panel III (NCEP/ATP III) criterion and tested the agreement of the two definitions, using the method suggested by Donner et al. [25].

We aimed to assess and compare the contribution of the four studied anthropometric indices (BMI, WC, HC and WHR) to cardio-metabolic risks, and WC is a condition component for diagnosing MetS according to the IDF criterion. Thus, we did not include WC as the risk index of cardio-metabolic risks when investigating the associations of BMI, WC, HC and WHR with cardiometabolic risk factors. So, we defined metabolic syndrome risk factors (MetS-rf) as having two or more of the following components: high BP, high TG, high FBG, and low HDL-C.

\section{Covariates}

Covariates were selected as a priori and collected using a self-administered questionnaire. The followings variables were included: age (years), sex (men, women), marital status (not married, get married, divorce or widowed), education levels (no school, primary school, junior high school, $\geq$ senior high school), tobacco use, alcohol drinking, and physical activity levels. More specifically, smoking status was categorized as current smokers (up to investigation date, continuous or cumulative smoking more than 100 cigarettes), former smokers (quit smoking more than 12 months ago), and non-smokers (never smoking). Drinking status were categorized as current drinkers (drinking alcohol at least once in the past 12 months), former drinkers (quit drinking more than 12 months ago), and non-drinkers (never drinking). Physical activity levels were categorized as high, moderate, and low levels, which have been detailed in the previous papers $[26,27]$. As the number of participants with high physical activity level was too small $(n=157)$, we thus combined "moderate" and "high" levels as one group to facilitate analysis.

\section{Statistical analysis}

Mean and standard deviation were used to describe normally distributed continuous variables (i.e., age, BMI, WC, HC, WHR, SBP, DBP, FBG, TC, HDL-C, and LDL-C), and median and quartile were used to describe non-normally distributed continuous variables (i.e.,TG). Frequency and percentage were used to describe the categorical data. Partial correlation analysis was used to evaluate the associations of the anthropometric indices with cardio-metabolic risk factors by gender, which were adjusted for age, family history of hypertension, family history of diabetes, family history of coronary heart disease, family history of stroke, smoking and drinking status, physical activity, marital status, and educational levels. Receiver operating characteristic (ROC) analysis was used to compare the abilities of different anthropometric indices to predict cardio-metabolic risk factors, and to determine optimal cut-off values of the selected anthropometric indices. We then used multivariate logistic regression model to assess the associations of the selected anthropometric indices with cardio-metabolic risk factors, which were adjusted for age, family history of hypertension, family history of diabetes, family history of coronary heart disease, family history of stroke, smoking and drinking status, physical activity, marital status, educational levels, $\mathrm{HC}$, and BMI levels. Due to anthropometric indices were highly correlated, BMI and $\mathrm{HC}$ were converted to categorical variables (BMI was categories as $<24 \mathrm{~kg} / \mathrm{m}^{2}, 24-28 \mathrm{~kg} / \mathrm{m}^{2}$, and $\geq 28 \mathrm{~kg} / \mathrm{m}^{2}$; $\mathrm{HC}$ was categorized as $\geq 100 \mathrm{~cm}$ and $<100 \mathrm{~cm}$ for women, and $\geq 99 \mathrm{~cm}$ and $<99 \mathrm{~cm}$ for men) to reduce 
Table 1 Characteristics of the study participants $(n=4664)$

\begin{tabular}{|c|c|}
\hline Variables & Values \\
\hline Age, years & $47.27 \pm 14.25$ \\
\hline Females, $n(\%)$ & $3027(64.90)$ \\
\hline \multicolumn{2}{|l|}{ Smoking status, $n(\%)$} \\
\hline Non-smokers & $4104(88.35)$ \\
\hline Former-smokers & $451(9.71)$ \\
\hline Current-smokers & $90(1.94)$ \\
\hline \multicolumn{2}{|l|}{ Drinking status, $n(\%)$} \\
\hline Non-drinkers & $4486(96.97)$ \\
\hline Former-drinkers & $87(1.88)$ \\
\hline Current-drinkers & 53 (1.15) \\
\hline \multicolumn{2}{|l|}{ Physical activity, $n(\%)$} \\
\hline Low strength & $4209(93.02)$ \\
\hline Moderate or high strength & $316(6.98)$ \\
\hline \multicolumn{2}{|l|}{ Marital status, $n(\%)$} \\
\hline Not married & $171(3.68)$ \\
\hline Get married & $4033(86.81)$ \\
\hline Divorce or widowed & $442(9.51)$ \\
\hline \multicolumn{2}{|l|}{ Educational level, $n(\%)$} \\
\hline No school & $448(9.64)$ \\
\hline Primary school & $2286(49.17)$ \\
\hline Junior high school & $1626(34.98)$ \\
\hline$\geq$ Senior high school & $289(6.22)$ \\
\hline Family history of hypertension, $n(\%)$ & $600(13.73)$ \\
\hline Family history of diabetes, $n(\%)$ & $150(3.47)$ \\
\hline Family history of coronary heart disease, $n(\%)$ & $334(7.68)$ \\
\hline Family history of stroke, $n(\%)$ & $7(0.16)$ \\
\hline Body mass index, $\mathrm{kg} / \mathrm{m}^{2}$ & $25.00 \pm 4.68$ \\
\hline Waist circumference, cm & $88.61 \pm 12.19$ \\
\hline Hip circumference, cm & $98.88 \pm 10.21$ \\
\hline Waist-to-hip ratio & $0.90 \pm 0.08$ \\
\hline Systolic blood pressure, mmHg & $113.94 \pm 19.58$ \\
\hline Diastolic blood pressure, $\mathrm{mmHg}$ & $72.20 \pm 12.32$ \\
\hline Fasting blood glucose, $\mathrm{mmol} / \mathrm{L}$ & $5.79 \pm 2.18$ \\
\hline Total cholesterol, mmol/L & $4.02 \pm 0.84$ \\
\hline Triglycerides, mmol/L & $1.16(0.83,1.71)$ \\
\hline High-density lipoprotein, mmol/L & $1.08 \pm 0.26$ \\
\hline Low-density lipoprotein, mmol/L & $2.66 \pm 0.75$ \\
\hline High blood pressure, $n(\%)$ & $1044(22.38)$ \\
\hline High fasting blood glucose, $n$ (\%) & $1936(41.51)$ \\
\hline High triglycerides, n (\%) & $1189(25.49)$ \\
\hline High total cholesterol, $n$ (\%) & $400(8.58)$ \\
\hline High low-density lipoprotein, $n$ (\%) & 749 (16.06) \\
\hline Low high-density lipoprotein, $n$ (\%) & $3334(71.48)$ \\
\hline
\end{tabular}

Table 1 Characteristics of the study participants $(n=4664)$

(Continued)

\begin{tabular}{|c|c|}
\hline Variables & Values \\
\hline \multicolumn{2}{|l|}{ Metabolic syndrome, $n$ (\%) } \\
\hline IDF criterion & $1838(39.41)$ \\
\hline NCEP/ATP III criterion & 1941 (41.62) \\
\hline
\end{tabular}

multicollinearity. All statistic analyses were carried out with the software SPSS version 22.0 (SPSS Inc., Chicago, IL, USA). Levels of statistical significance were set at a two-tailed $p$ value $<0.05$.

\section{Results}

Mean age of the participants was 47 years old and $64.90 \%$ of them were women (Table 1). Most participants were non-drinkers (96.97\%), non-smokers (88.35\%), and had low physical activity level (93.02\%). The prevalence of high BP, high FBG, high TG, high LDL-C, and low HDL-C levels were 22.38, 41.51, 25.49, 16.06 , and $71.48 \%$, respectively. The overall prevalence of MetS according to the IDF and NCEP/ATP III definitions was 39.41 and $41.62 \%$, respectively, and the Kappa coefficient of the two definitions was 0.954 (Additional file 1: Table S1).

Table 2 summarizes gender-specific associations between the studied anthropometric indices and cardiometabolic risk factors. In men, higher WC, HC, BMI, and WHR were all significantly associated with higher levels of SBP ( $r$ was $0.205,0.159,0.167$ and 0.123 , respectively, all $p<0.001$ ), DBP ( $r$ was $0.233,0.194,0.177$ and 0.118 , respectively, all $p<0.001$ ), FBG ( $r$ was 0.085 , $0.062,0.041$ and 0.050 , respectively, $p$ values ranging from $<0.001$ to 0.022 ), TC ( $r$ was $0.196,0.161,0.154$ and 0.115 , respectively, all $p<0.001$ ), TG ( $r$ was 0.343 , $0.272,0.309,0.204$, respectively, all $p<0.001)$, and LDL-C ( $r$ was $0.138,0.112,0.113$ and 0.088 , respectively, all $p<0.001$ ), as well as lower levels of HDL-C ( $r$ was $-0.328,-0.221,-0.326$ and -0.249 , respectively, all $p<0.001$ ). In addition, we observed that, compared with other anthropometric indices (i.e. HC, BMI, and WHR), WC showed the strongest associations with the cardio-metabolic risk factors (all $p<0.001$, Table 2 and Additional file 1: Table S2). For women, similar results were observed (Table 2 and Additional file 1: Table S2).

Table 3 shows the results of the ROC analyses. In men, WC was generally the best anthropometric predictive index for nearly all cardio-metabolic risk factors, with areas under the ROC curves (AUCs) ranging from 0.58 for high FBG to 0.74 for high TG. BMI also showed high discriminative abilities in predicting high TG and low HDL-C, but its AUC values were only equal to those of WC. The optimal cut-offs for determining high BP, 
Table 2 Partial correlation coefficients between simple anthropometric indices and cardio-metabolic risk factors

\begin{tabular}{|c|c|c|c|c|c|c|c|c|}
\hline & \multicolumn{2}{|l|}{ WC } & \multicolumn{2}{|l|}{$\mathrm{HC}$} & \multicolumn{2}{|l|}{$\mathrm{BMI}$} & \multicolumn{2}{|l|}{ WHR } \\
\hline & $r$ & $p$-value & $r$ & $p$-value & $r$ & $p$-value & $r$ & $p$-value \\
\hline \multicolumn{9}{|l|}{ Males } \\
\hline SBP & 0.205 & $<0.001$ & 0.159 & $<0.001$ & 0.167 & $<0.001$ & 0.123 & $<0.001$ \\
\hline DBP & 0.233 & $<0.001$ & 0.194 & $<0.001$ & 0.177 & $<0.001$ & 0.118 & $<0.001$ \\
\hline FBG & 0.085 & $<0.001$ & 0.062 & 0.009 & 0.041 & 0.022 & 0.050 & 0.002 \\
\hline $\mathrm{TC}$ & 0.196 & $<0.001$ & 0.161 & $<0.001$ & 0.154 & $<0.001$ & 0.115 & $<0.001$ \\
\hline $\mathrm{TG}$ & 0.343 & $<0.001$ & 0.272 & $<0.001$ & 0.309 & $<0.001$ & 0.204 & $<0.001$ \\
\hline HDL-C & -0.328 & $<0.001$ & -0.221 & $<0.001$ & -0.326 & $<0.001$ & -0.249 & $<0.001$ \\
\hline LDL-C & 0.138 & $<0.001$ & 0.112 & $<0.001$ & 0.113 & $<0.001$ & 0.088 & $<0.001$ \\
\hline \multicolumn{9}{|l|}{ Females } \\
\hline SBP & 0.190 & $<0.001$ & 0.170 & $<0.001$ & 0.167 & $<0.001$ & 0.086 & $<0.001$ \\
\hline DBP & 0.186 & $<0.001$ & 0.172 & $<0.001$ & 0.165 & $<0.001$ & 0.079 & $<0.001$ \\
\hline FBG & 0.106 & $<0.001$ & 0.066 & $<0.001$ & 0.079 & $<0.001$ & 0.081 & $<0.001$ \\
\hline $\mathrm{TC}$ & 0.214 & $<0.001$ & 0.187 & $<0.001$ & 0.212 & $<0.001$ & 0.101 & $<0.001$ \\
\hline TG & 0.232 & $<0.001$ & 0.185 & $<0.001$ & 0.244 & $<0.001$ & 0.135 & $<0.001$ \\
\hline $\mathrm{HDL}-\mathrm{C}$ & -0.226 & $<0.001$ & -0.194 & $<0.001$ & -0.203 & $<0.001$ & -0.119 & $<0.001$ \\
\hline LDL-C & 0.215 & $<0.001$ & 0.198 & $<0.001$ & 0.199 & $<0.001$ & 0.091 & $<0.001$ \\
\hline
\end{tabular}

Abbreviations: $B M I$ body mass index, $D B P$ diastolic blood pressure, $F B G$ fasting blood glucose, $H C$ hip circumference, $H D L-C$ high-density lipoprotein, $L D L-C$ lowdensity lipoprotein, SBP systolic blood pressure, $T C$ total cholesterol, $T G$ triglycerides, WC waist circumference, WHR waist-to-hip ratio. Adjusted for age, family history of hypertension, family history of diabetes, family history of coronary heart disease, and family history of stroke, smoking and drinking status, physical activity, marital status, educational levels

high FBG, high TG, high LDL-C, low HDL-C, and MetS-rf were $90.50 \mathrm{~cm}, 97.50 \mathrm{~cm}, 90.50 \mathrm{~cm}, 91.50 \mathrm{~cm}, 89.50 \mathrm{~cm}$ and $90.50 \mathrm{~cm}$, respectively. Similarly, in women, WC was also the best anthropometric predictive index for all the cardio-metabolic risk factors. The AUCs were 0.69 for high
BP, 0.60 for high FBG, 0.72 for high TG, 0.66 for high LDL-C, 0.63 for low HDL-C, and 0.70 for MetS-rf, the corresponding optimal cut-offs of combined sensitivity and specificity were $86.50 \mathrm{~cm}, 87.50 \mathrm{~cm}, 90.50 \mathrm{~cm}, 86.50 \mathrm{~cm}$, $87.50 \mathrm{~cm}$ and $86.50 \mathrm{~cm}$, respectively.

Table 3 Areas under the ROC by anthropometric indices for cardio-metabolic risk factors

\begin{tabular}{|c|c|c|c|c|c|c|c|c|}
\hline & \multicolumn{2}{|l|}{ WC } & \multicolumn{2}{|l|}{$\mathrm{HC}$} & \multicolumn{2}{|l|}{ BMI } & \multicolumn{2}{|l|}{ WHR } \\
\hline & $\mathrm{AUC}(95 \% \mathrm{Cl})$ & Cut point & $\operatorname{A\cup C}(95 \% \mathrm{Cl})$ & Cut point & $\mathrm{AUC}(95 \% \mathrm{Cl})$ & Cut point & $\mathrm{AUC}(95 \% \mathrm{Cl})$ & Cut point \\
\hline \multicolumn{9}{|l|}{ Males } \\
\hline MetS-rf & $0.70(0.67,0.72)$ & 90.50 & $0.65(0.63,0.68)$ & 100.05 & $0.68(0.66,0.71)$ & 25.02 & $0.67(0.64,0.69)$ & 0.908 \\
\hline High BP & $0.66(0.63,0.69)$ & 90.50 & $0.63(0.60,0.67)$ & 101.50 & $0.62(0.59,0.66)$ & 23.71 & $0.64(0.61,0.67)$ & 0.905 \\
\hline High FBG & $0.58(0.55,0.61)$ & 97.50 & $0.55(0.53,0.58)$ & 100.50 & $0.55(0.52,0.58)$ & 23.51 & $0.56(0.54,0.59)$ & 0.951 \\
\hline High TG & $0.74(0.71,0.76)$ & 90.50 & $0.70(0.68,0.73)$ & 101.50 & $0.75(0.72,0.77)$ & 25.38 & $0.67(0.64,0.69)$ & 0.902 \\
\hline High LDL-C & $0.61(0.57,0.65)$ & 91.50 & $0.60(0.56,0.64)$ & 101.50 & $0.60(0.56,0.64)$ & 22.25 & $0.59(0.55,0.62)$ & 0.900 \\
\hline Low HDL-C & $0.66(0.63,0.69)$ & 89.50 & $0.62(0.60,0.65)$ & 99.50 & $0.66(0.64,0.69)$ & 24.75 & $0.63(0.60,0.66)$ & 0.905 \\
\hline \multicolumn{9}{|l|}{ Females } \\
\hline MetS-rf & $0.70(0.68,0.72)$ & 86.50 & $0.64(0.62,0.66)$ & 97.50 & $0.66(0.64,0.68)$ & 24.15 & $0.67(0.65,0.69)$ & 0.864 \\
\hline High BP & $0.69(0.67,0.71)$ & 86.50 & $0.63(0.61,0.66)$ & 98.50 & $0.63(0.60,0.65)$ & 23.93 & $0.67(0.64,0.69)$ & 0.866 \\
\hline High FBG & $0.60(0.58,0.62)$ & 87.50 & $0.56(0.54,0.58)$ & 100.50 & $0.57(0.55,0.59)$ & 24.22 & $0.60(0.58,0.62)$ & 0.879 \\
\hline High TG & $0.72(0.70,0.74)$ & 90.50 & $0.68(0.65,0.70)$ & 100.50 & $0.71(0.69,0.73)$ & 23.92 & $0.67(0.65,0.69)$ & 0.881 \\
\hline High LDL-C & $0.66(0.63,0.68)$ & 86.50 & $0.63(0.61,0.66)$ & 100.00 & $0.62(0.60,0.65)$ & 23.92 & $0.62(0.60,0.64)$ & 0.863 \\
\hline Low HDL-C & $0.63(0.60,0.65)$ & 87.50 & $0.61(0.59,0.64)$ & 95.00 & $0.62(0.59,0.64)$ & 22.46 & $0.59(0.56,0.61)$ & 0.862 \\
\hline
\end{tabular}

Abbreviations: $A U C$ areas under the ROC curves, $B P$ blood pressure, $B M I$ body mass index, $C l$ confidence interval, $F B G$ fasting blood glucose, $H C$ hip circumference, $H D L-C$ high-density lipoprotein, $L D L-C$ low-density lipoprotein, MetS-rf metabolism syndrome risk factors, TG triglycerides, WC waist circumference, WHR waist-to-hip ratio 
Table 4 summarizes gender-specific associations between WC and prevalence of cardio-metabolic risk factors (Table 4). Generally, compared with participants with WC below cut-off value, those who had WC over cut-off value showed higher risk odds of MetS-rf (e.g., OR was 2.12 in men and 1.61 in women, both $p<0.001$ ). Additionally, WC also showed significant associations with high BP (men: $\mathrm{OR}=1.43, p=0.071$; women: $\mathrm{OR}=1.54, p=0.007$ ), high FBG (men: $\mathrm{OR}=2.00, p<0.001$; women: $\mathrm{OR}=1.34$, $p=0.017$ ), high TG (men: $\mathrm{OR}=2.83$; women: $\mathrm{OR}=1.94$, both $p<0.001$ ), high LDL-C (men: $\mathrm{OR}=1.93, p=0.004$; women: $\mathrm{OR}=1.43$, both $p=0.033$ ), and low HDL-C (men: $\mathrm{OR}=1.83$; women: $\mathrm{OR}=1.68$, both $p<0.001$ ).

\section{Discussion}

In this large population-based study, we observed that the prevalence of MetS was 39.41\% in the rural Uyghur adults from Xinjiang Uyghur Autonomous Region. In addition, we found that WC performed better than the other obesity indices in predicting the cardio-metabolic risks. WC of $86.50 \mathrm{~cm}$ for women and $90.50 \mathrm{~cm}$ for men were the optimal cut-off values to screen cardio-metabolic risk factors.

\section{The prevalence of the cardio-metabolic risk factors}

The MetS prevalence in our current study was much higher than those previously reported in other Chinese populations. A cross-sectional survey conducted in 14

Table 4 Associations between anthropometric indices and the risk of cardio-metabolic risk factors by gender

\begin{tabular}{lll}
\hline & OR $(95 \% \mathrm{Cl})$ & $p$-value \\
\hline Males & $2.12(1.54,2.93)$ & $<0.001$ \\
MetS-rf & $1.43(0.97,2.11)$ & 0.071 \\
High BP & $2.00(1.44,2.78)$ & $<0.001$ \\
High FBG & $2.83(1.94,4.12)$ & $<0.001$ \\
High TG & $1.93(1.24,3.01)$ & 0.004 \\
High LDL-C & $1.83(1.32,2.54)$ & $<0.001$ \\
Low HDL-C & & $<0.001$ \\
Females & $1.61(1.26,2.05)$ & 0.007 \\
MetS-rf & $1.54(1.12,2.10)$ & 0.017 \\
High BP & $1.34(1.05,1.70)$ & $<0.001$ \\
High FBG & $1.94(1.48,2.55)$ & 0.033 \\
High TG & $1.43(1.03,1.99)$ & $<0.001$ \\
High LDL-C & $1.68(1.27,2.23)$ & \\
Low HDL-C & &
\end{tabular}

Abbreviations: $B P$ blood pressure, $C l$ confidence interval, $F B G$ fasting blood glucose, $H D L-C$ high-density lipoprotein, $L D L-C$ low- density lipoprotein, MetS-rf metabolism syndrome risk factors, $O R$ odds ratio, $T G$ triglycerides. WC as category variable (cut-point values) for analysis; Adjusted age, family history of hypertension, family history of diabetes, family history of coronary heart disease, and family history of stroke, smoking and drinking status, physical activity, marital status, educational levels, hip circumference (females: $\geq 100$ $\mathrm{cm}$; males: $\geq 99 \mathrm{~cm}$ ), and body mass index categories provinces with 47,325 adults showed that the average prevalence of MetS was $24.2 \%$ in China [3]. Another study of 15,020 rural multi-ethnic adults from Xinjiang reported that the prevalence of MetS was 15.90 and $23.36 \%$ according to NCEP/ATP III and IDF criterions, respectively [14]. In particular, in a study of 3542 Uyghurs aged 18 years or older, $\mathrm{He}$ et al. reported that the prevalence of MetS was 21.3\% (IDF criterion) [18]. The high prevalence of MetS observed in our current study is likely due to the high prevalence of elevated FBG (45.51\%) and reduced HDL-C levels (71.48\%). The main reason for these high prevalence rates may be mainly related to the local dietary habits. The dietary pattern in Kashgar city is characterized by low vegetable consumption and high fresh meat due to cold climate conditions and heavy labor. The cold climate makes it difficult for the local residents to plant and store fresh vegetables. Due to low income and inconvenient transportation, vegetables are not easy to get for the local residents. Previously, a body of evidence has suggested that vegetables intake was significantly negatively associated with FBG levels [28, 29]. Furthermore, previous studies reported a significant positive relationship of red meat intake with dyslipidemia risk and MetS [30, 31]. Residents in Kashgar area consumed a lot of red meat such as beef and mutton which contains high cholesterol and saturated fat levels. Numerous studies have suggested that red meat intake was associated with insulin resistance and chronic state of inflammation, which were the underlying mechanisms for MetS [32, 33].

We also found that the prevalence of MetS was higher in women $(43.41 \%)$ than in men $(32.01 \%)$, which is in line with most previous studies [14, 18, 34]. The high MetS prevalence in women observed in the current study could be explained by the higher frequency of obesity among women in Xinjiang Uyghurs. For example, in this survey, most of the women participants were housewives, who were mainly responsible for taking care of their families and were lack of heavy physical activities. Therefore, Uyghur women usually have a higher prevalence of obesity [35]. These findings suggest that women should be prioritized in planning the future health care strategies in far Northwestern China.

\section{Optimal cut-off points of WC on cardio-metabolic risk factors}

Obesity, especially visceral adiposity, is widely accepted to be associated with cardio-metabolic markers. Although WC is the most commonly used anthropometric index to reflect visceral adiposity and predict cardio-metabolic risk factors, studies from different populations have yielded inconsistent results. For example, Pan et al. compared the prediction effect of different obesity indices for MetS in 10,100 Chinese southerners 
and found that BMI and WHtR might be more useful than WC for predicting $\geq 2$ non-adipose components of MetS [36]. Additionally, Yu et al. reported that WC was the optimal predictor for CVD in Chinese men, while WHtR in women [37]. However, Cheong et al. showed that there was no significant difference in the discriminative abilities of WC and BMI in predicting MetS in Malaysia population [12], and the result was consistent with the subsequent prospective cohort study conducted among Northeastern Chinese [38]. Our results indicated that WC was the best predictor for predicting cardio-metabolic risks and its individual components. The exact reasons for these inconsistent results between our and those previous studies were unclear, but may be closely related to ethnicity (genetic background) and lifestyles, especially dietary habits. Therefore, it would be necessary to explore and recommend an optimal anthropometric index for a special area and/or ethnicity. In the study, we found that $\mathrm{WC} \geq 86.50 \mathrm{~cm}$ in women and $\geq 90.50 \mathrm{~cm}$ in men might be suitable for assessing the likelihood of MetS in Uyghur adults. In a systematic MEDLINE search, we found only two relevant epidemiological studies on the accuracy of WC as diagnostic test for MetS of Uyghur population. Specifically, in a study of 256 Uyghur individuals, Lu et al. reported that $89 \mathrm{~cm}$ for women and $93 \mathrm{~cm}$ for men were the best cut-off WC values to predict MetS [17]. Another study of 3542 Uyghur adults showed that the cut-off values of WC for predicting MetS in women and men were $82 \mathrm{~cm}$ and 85 $\mathrm{cm}$, respectively [18]. By contrast, our study adopted a random sampling strategy and had a larger sample size of representative population, thus we believe our estimations would be more precise and robust.

\section{Limitations and strengths}

In interpreting the findings of the current study, several limitations should be acknowledged. First, the present study used a cross-sectional design, which limits the interpretation of causality of associations between WC and the cardio-metabolic risk factors. Second, we used a questionnaire to collect information on covariates such as smoking, drinking, and physical activity, which might have caused recall biases. In addition, information on some variables (e.g., alcohol use) were not detailed enough, which might have cause misclassification and potential residuals. Third, although we collected and incorporated a rich set of variables into the models, information on other potential confounders such as dietary habits, environmental hazards, genes involved in cardio-metabolic risk factors were not considered, which might have compromised the estimates. Despite these limitations, our study still has several advantages. First, our study has a relatively large sample size with high response rate, which enhances the statistical power and the accuracy of the estimates. Second, all participants were of Uyghur nationality and from the same county, which improves the homogeneity of the study population and thus increases the validity of statistical analysis. Third, to the best of our knowledge, our findings provide the first evidence on the cut-off values to discriminate individuals with MetS in Uyghur population in Kashgar region, and evaluated the risk odds of cardio-metabolic risk factors when WC was over the calculated cut-off value.

\section{Conclusions}

In summary, our study shows that the prevalence of MetS in Xinjiang Uyghur nationality adults was high, especially in women. In addition, we found that WC had the strongest predictive power for identifying cardiometabolic risk factors, and WC cut-off points of 86.50 $\mathrm{cm}$ for women and $90.50 \mathrm{~cm}$ for men were optimal for discriminating individuals with MetS. However, given the limitations of our study, further well-designed longitudinal studies are warranted to confirm our findings.

\section{Additional file}

Additional file 1: Table S1. Agreement between IDF defined and the updated NCEP/ATP III defined metabolic syndrome. Number of cases, kappa statistic $(95 \% \mathrm{Cls})$, and $p$ value. Table S2. The generalized linear regression analysis between simple anthropometric indices and cardiometabolic risk factors. (DOCX $22 \mathrm{~kb}$ )

\section{Abbreviations \\ APOA5: Apolipoprotein A-V; AUCs: Areas under the ROC curves; BMI: Body mass index; BP: Blood pressure; CETP: Cholesteryl ester transfer protein; CVD: Cardiovascular disease; DBP: Diastolic blood pressure; FBG: Fasting blood glucose; HC: Hip circumference; HDL-C: High-density lipoprotein; IDF: International Diabetes Federation; LDL-C: Low- density lipoprotein; LPL: Lipoprotein lipase; MetS: Metabolic syndrome; NCEP/ATP III: National Cholesterol Education Program/Adult Treatment Panel III; OR: Odds ratio; ROC: Receiver operating characteristic; SBP: Systolic blood pressure; TC: Total cholesterol; TG: Triglycerides; WC: Waist circumference; WHR: Waist-to-hip ratio; WHtR: Waist-to-height ratio}

\section{Acknowledgements \\ We would like to thank all of the participants in this study. Also, we would like to thank Dr. Bo-Yi Yang from Sun Yat-sen University for his thoughtful suggestions and revisions.}

\section{Funding}

This research was funded by the Science and Technology Project of Guangdong Province (2014A020209006) and the National Natural Science Foundation of China (81803196)

\section{Availability of data and materials}

The datasets used and/or analysed during the current study are available from the corresponding author upon reasonable request.

\section{Authors' contributions}

$Z Z, S F$, and ZY conceived of and designed the experiments. SF, ZX, JY, ZZ, $A B$, and NN performed the experiments. ZZ and SF analyzed the data. TW, $J$, and YW contributed reagents/materials/analysis tools. ZZ and SF wrote the paper. All authors have read and approved the final manuscript. 


\section{Ethics approval and consent to participate}

The study was approved by the Ethics Committee of Guangzhou Center for Disease Control (Identification code: GZCDC-ER[A]2016007). A written informed consent was obtained from all participants.

\section{Consent for publication}

Not applicable.

\section{Competing interests}

The authors declare that they have no competing interests.

\section{Publisher's Note}

Springer Nature remains neutral with regard to jurisdictional claims in published maps and institutional affiliations.

\section{Author details}

${ }^{1}$ Guangzhou Center for Disease Control and Prevention, No. 1 Qide Road, Guangzhou, Baiyun Area, Guangzhou 510440, China. ${ }^{2}$ Shufu Center for Disease Control and Prevention, Kashgar 844100, China. ${ }^{3}$ Kashgar Prefecture Center for Disease Control and Prevention, Kashgar 844100, China.

\section{Received: 11 October 2018 Accepted: 11 April 2019}

Published online: 21 May 2019

\section{References}

1. Alberti KG, Eckel RH, Grundy SM, Zimmet PZ, Cleeman Jl, Donato KA, et al. Harmonizing the metabolic syndrome: a joint interim statement of the International Diabetes Federation Task Force on Epidemiology and Prevention; National Heart, Lung, and Blood Institute; American Heart Association; World Heart Federation; International Atherosclerosis Society; and International Association for the Study of Obesity. Circulation. 2009; 120(16):1640-5.

2. Gu D, Reynolds K, Wu X, Chen J, Duan X, Reynolds RF, et al. Prevalence of the metabolic syndrome and overweight among adults in China. Lancet. 2005;365(9468):1398-405

3. Zhou HC, Lai YX, Shan ZY, Jia WP, Yang WY, Lu JM, et al. Effectiveness of different waist circumference cut-off values in predicting metabolic syndrome prevalence and risk factors in adults in China. Biomed Environ Sci. 2014;27(5):325-34.

4. Song QB, Zhao Y, Liu YQ, Zhang J, Xin SJ, Dong GH. Sex difference in the prevalence of metabolic syndrome and cardiovascular-related risk factors in urban adults from 33 communities of China: The CHPSNE study. Diab Vasc Dis Res. 2015;12(3):189-98.

5. Saklayen MG. The Global Epidemic of the Metabolic Syndrome. Curr Hypertens Rep. 2018;20(2):12.

6. Cornier MA, Dabelea D, Hernandez TL, Lindstrom RC, Steig AJ, Stob NR, van Pelt RE, Wang H, Eckel RH. The metabolic syndrome. Endocr Rev. 2008;29: 777-822. https://doi.org/10.1210/er.2008-0024.

7. Clementi EA, Talusan A, Vaidyanathan S, Veerappan A, Mikhail M, Ostrofsky $D$, et al. Metabolic syndrome and air pollution: a narrative review of their cardiopulmonary effects. Toxics. 2019;7(1):pii:E6. https://doi.org/10.3390/ tocixs7010006.

8. Fall T, Ingelsson E. Genome-wide association studies of obesity and metabolic syndrome. Mol Cell Endocrinol. 2014;382(1):740-57.

9. Wang F, Wu S, Song Y, Tang X, Marshall R, Liang M, et al. Waist circumference, body mass index and waist to hip ratio for prediction of the metabolic syndrome in Chinese. Nutr Metab Cardiovasc Dis. 2009;19(8):542-7.

10. Wicklow BA, Becker A, Chateau D, Palmer K, Kozyrskij A, Sellers EA. Comparison of anthropometric measurements in children to predict metabolic syndrome in adolescence: analysis of prospective cohort data. Int J Obes. 2015;39(7):1070-8.

11. Jaeschke L, Steinbrecher A, Pischon T. Measurement of waist and hip circumference with a body surface scanner: feasibility, validity, reliability, and correlations with markers of the metabolic syndrome. PLoS One. 2015;10(3): e0119430.

12. Cheong KC, Ghazali SM, Hock LK, Subenthiran S, Huey TC, Kuay LK, et al. The discriminative ability of waist circumference, body mass index and waist-to-hip ratio in identifying metabolic syndrome: Variations by age, sex and race. Diabetes Metab Syndr. 2015;9(2):74-8.

13. Chen BD, Yang YN, Ma YT, Pan S, He CH, Liu F, et al. Waist-to-Height Ratio and Triglycerides/High-Density Lipoprotein Cholesterol Were the Optimal
Predictors of Metabolic Syndrome in Uighur Men and Women in Xinjiang, China. Metab Syndr Relat Disord. 2015;13(5):214-20.

14. Guo H, Gao X, Ma R, Liu J, Ding Y, Zhang M, et al. Prevalence of Metabolic Syndrome and its Associated Factors among Multi-ethnic Adults in Rural Areas in Xinjiang, China. Sci Rep. 2017;7(1):17643.

15. Zohra R, Song MS, lliham N, Dolikun M. A comparative study on characterizations of genetic recombination hotspots in PPARG gene between Kirgiz and Uyghur ethnic groups in Xinjiang. Zhonghua Yi Xue Za Zhi. 2016;96:2487-92. https://doi.org/10.3760/cma.j.issn.0376-2491. 2016.31.010.

16. Pan Y, Wang T, Li Y, Guan T, Lai Y, Shen Y, et al. Association of ACE2 polymorphisms with susceptibility to essential hypertension and dyslipidemia in Xinjiang, China. Lipids Health Dis. 2018;17(1):241.

17. Lu Q, Xie Z, Zhang H, Ren J. Evaluation of the appropriate diagnostic threshold of waist circumference for the cardiometabolic syndrome in Chinese Uygur adults. J Cardiometab Syndr. 2009;4(2):120-5.

18. He J, Ma R, Liu J, Zhang M, Ding Y, Guo H, et al. The Optimal EthnicSpecific Waist-Circumference Cut-Off Points of Metabolic Syndrome among Low-Income Rural Uyghur Adults in Far Western China and Implications in Preventive Public Health. Int J Environ Res Public Health. 2017;14(2):pii: E158.

19. National Center for Health Statistics (NCHS) Waist Circumference Measurement Methodology Study: National Health and Nutrition ExaminationSurvey, 2016 [Internet] 2019 [cited 2019 May 15]. Available from: https://www.cdc.gov/nchs/data/series/sr_02/sr02_182-508.pdf

20. Reidpath DD, Cheah JC, Lam FC, Yasin S, Soyiri I, Allotey P. Validity of selfmeasured waist and hip circumferences: results from a community study in Malaysia. Nutr J. 2013;12:135.

21. Kirkendall WM, Feinleib M, Freis ED, Mark AL. Recommendations for human blood pressure determination by sphygmomanometers. Subcommittee of the AHA Postgraduate Education Committee. Stroke. 1981;12(4):555A-64A.

22. Pickering TG, Hall JE, Appel $L$, Falkner BE, Graves J, Hill MN, et al. Recommendations for blood pressure measurement in humans and experimental animals: part 1: blood pressure measurement in humans: a statement for professionals from the Subcommittee of Professional and Public Education of the American Heart Association Council on High Blood Pressure Research. Circulation. 2005;111(5):697-716.

23. Alberti KG, Zimmet P, Shaw J. Metabolic syndrome-a new world-wide definition. A Consensus Statement from the International Diabetes Federation. Diabet Med. 2006;23:469-80.

24. Guidelines for prevention and treatment of adult dyslipidemia China designated Joint Committee. Guide to China Adult dyslipidemia prevention. Chin J Geriatr Heart Brain Vessel Dis. 2008;10:390-409.

25. Donner A, Eliasziw M, Klar N. Testing the homogeneity of kappa statistics. Biometrics. 1996;52:176-83.

26. Fan S, Yang B, Zhi X, He J, Ma P, Yu L, et al. Neck circumference associated with arterial blood pressures and hypertension: A cross-sectional community-based study in northern Han Chinese. Sci Rep. 2017;7(1):2620.

27. Wu F, Guo Y, Chatterji S, Zheng Y, Naidoo N, Jiang Y, et al. Common risk factors for chronic non-communicable diseases among older adults in China, Ghana, Mexico, India, Russia and South Africa: the study on global AGEing and adult health (SAGE) wave 1. BMC Public Health. 2015;15:88.

28. Sabaté J, Wien M. A perspective on vegetarian dietary patterns and risk of metabolic syndrome. Br J Nutr. 2015:113(Suppl 2):S136-43.

29. Mercier R, Perron J, Weisnagel SJ, Robitaille J. Associations between fruit and vegetables intake and abnormal glucose tolerance among women with prior gestational diabetes mellitus. Eur J Nutr. 2018. https://doi.org/10.1007/ s00394-018-1669-2.

30. Mager DR, Mazurak V, Rodriguez-Dimitrescu C, Vine D, Jetha M, Ball G, et al. A meal high in saturated fat evokes postprandial dyslipemia, hyperinsulinemia, and altered lipoprotein expression in obese children with and without nonalcoholic fatty liver disease. JPEN J Parenter Enteral Nutr. 2013;37(4):517-28.

31. Azadbakht L, Esmaillzadeh A. Red meat intake is associated with metabolic syndrome and the plasma C-reactive protein concentration in women. J Nutr. 2009;139(2):335-9.

32. Tangvarasittichai S, Pimanprom A, Choowet A, Tangvarasittichai O. Association of iron overload and oxidative stress with insulin resistance in transfusion-dependent beta-thalassemia major and beta-thalassemia/ $\mathrm{HbE}$ patients. Clin Lab. 2013;59(7-8):861-8. 
33. Turner KM, Keogh JB, Meikle PJ, Clifton PM. Changes in Lipids and Inflammatory Markers after Consuming Diets High in Red Meat or Dairy for Four Weeks. Nutrients. 2017;9(8):pii: E886.

34. Li R, Li W, Lun Z, Zhang H, Sun Z, Kanu JS, et al. Prevalence of metabolic syndrome in Mainland China: a meta-analysis of published studies. BMC Public Health. 2016;16:296.

35. He J, Guo S, Liu J, Zhang M, Ding Y, Zhang J, et al. Ethnic differences in prevalence of general obesity and abdominal obesity among low-income rural Kazakh and Uyghur adults in far western China and implications in preventive public health. PLoS One. 2014;9(9):e106723.

36. Pan J, Wang M, Ye Z, Yu M, Shen Y, He Q, et al. Optimal cut-off levels of obesity indices by different definitions of metabolic syndrome in a southeast rural Chinese population. J Diabetes Investig. 2016;7(4):594-600

37. Yu J, Tao Y, Tao Y, Yang S, Yu Y, Li B, et al. Optimal cut-off of obesity indices to predict cardiovascular disease risk factors and metabolic syndrome among adults in Northeast China. BMC Public Health. 2016;16(1):1079.

38. Wang H, Liu A, Zhao T, Gong X, Pang T, Zhou Y, et al. Comparison of anthropometric indices for predicting the risk of metabolic syndrome and its components in Chinese adults: a prospective, longitudinal study. BMJ Open. 2017;7(9):e016062

Ready to submit your research? Choose BMC and benefit from:

- fast, convenient online submission

- thorough peer review by experienced researchers in your field

- rapid publication on acceptance

- support for research data, including large and complex data types

- gold Open Access which fosters wider collaboration and increased citations

- maximum visibility for your research: over $100 \mathrm{M}$ website views per year

At BMC, research is always in progress.

Learn more biomedcentral.com/submissions 